\title{
Custo de produção de fêmeas bovinas leiteiras durante as fases de cria e de recria: um estudo de caso
}

\author{
[Producing cost of dairy cattle females during lactation and recreates phase: study case on a \\ production system in the State of Minas Gerais]
}

\section{"Artigo Científico/Scientific Article"}

\author{
Eduardo Mitke Brandão Reis ${ }^{1}$, Marcos Aurélio Lopes ${ }^{2 *}$, Glauber dos Santos ${ }^{3}$, \\ Antônio Marcos Guimarães ${ }^{2}$
}

\author{
${ }^{1}$ Universidade Federal do Acre (UFAC), Rio Branco - AC, Brasil. \\ ${ }^{2}$ Programa de Pós-Graduação em Ciências Veterinárias, Universidade Federal de Lavras (UFLA), Lavras - MG, Brasil. \\ ${ }^{3}$ PECEGE, Escola Superior de Agricultura Luiz de Queiroz (ESALQ), Universidade de São Paulo (USP), Piracicaba - \\ SP, Brasil. \\ *Autor para correspondência/Corresponding author: E-mail: malopes@dmv.ufla.br
}

\begin{abstract}
Resumo
Objetivou-se estimar o custo de produção de fêmeas bovinas da raça holandesa nas fases de cria (42 animais) e recria (59 animais) e identificar os componentes que exerceram maiores representatividades sobre os custos finais (custo operacional efetivo - COE e custo operacional total - COT) da atividade. Os dados foram coletados em uma fazenda produtora de leite, localizada em Ijaci, no sul de Minas Gerais, durante os meses de março a junho de 2014. Para o cálculo do COT considerou-se todos os custos operacionais efetivos, bem como a depreciação das instalações e equipamentos. O COT durante a fase de cria foi de $\mathrm{R} \$ 571,03$, enquanto que para a fase de recria foi de $\mathrm{R} \$ 6.606,43$. Os itens componentes que exerceram maiores representatividades sobre os custos da atividade na fase de cria foram, em ordem decrescente, alimentação, sêmen e mão-de-obra. Na fase de recria foram, respectivamente, em ordem decrescente, alimentação, mão de obra e aquisição de bezerras. Conclui-se que, nessas condições, a atividade cria e recria foi inviável economicamente, visto que o preço de venda é inferior ao custo operacional efetivo.
\end{abstract}

Palavras-chave: análise econômica; bovinocultura de leite; gestão.

\begin{abstract}
The aim was to calculate the production cost of Holstein cows in the weaning (42 animals) and post-weaning (59 animals) phases and to identify the components that have the greatest influence on the final operation costs (effective operating cost - COE and total operating cost-COT) of the activity. The data were collected on a dairy farm located in Ijaci, in the South of Minas Gerais, during the months of March to June, 2014. To calculate the total operational cost (COT), all the effective operational expenses were considered, as well as the depreciation of facilities and equipment. The COT during the growing phase was R $\$ 571,03$, while for the rearing phase, it was $\mathrm{R} \$ 6,606$. The components and items, respectively, which exerted greater emphasis on weaning costs were, in descending order, food, semen, and labor. For post-weaning, they were, in descending order, food, labor, and procurement of calves. It is concluded that, in these conditions, breeding and rearing was economically viable since the selling price is less than the effective operating cost.
\end{abstract}

Keywords: dairy cattle; economic analysis; management.

\section{Introdução}

A criação de fêmeas bovinas deve ser considerada como uma das principais atividades da fazenda produtora de leite, uma vez que a melhoria genética do rebanho depende da substituição de

vacas velhas por animais jovens e com potencial produtivo mais elevado (Santos e Lopes, 2014).

Sistemas de produção leiteira apresentam uma complexidade particular no gerenciamento de 
custos, uma vez que existem diferentes centros produtivos (produção de alimentos volumosos e grãos; criação de fêmeas; produção de leite) os quais se interligam e apresentam entrada e saída de recursos financeiros em momentos bem distintos que exigem habilidade gerencial dos gestores. Assim, a disciplina e o conhecimento da melhor metodologia de alocar os recursos tornam-se imprescindíveis para o sucesso da organização (Caselli e Assis, 2011).

A determinação dos custos de produção de fêmeas bovinas leiteiras é uma tarefa bastante complexa e demorada, pois envolve uma grande quantidade de cálculos, detalhes e requer muita atenção (Lopes e Carvalho, 2000). Criar fêmeas destinadas à reposição de matrizes produtoras leiteiras tem sido uma tarefa onerosa e desafiadora para a grande maioria dos produtores, pois, durante esse período, o produtor despende muitos recursos que poderiam ser aplicados em outra área, como, por exemplo, aquisição de tecnologias, manejo de pastagem, entre outros (Santos e Lopes, 2014). Além disso, elas ocupam uma área grande dentro da propriedade, que poderia ser destinada a animais em fase de produção de leite.

Os dados obtidos da apuração dos custos de produção têm sido utilizados para diferentes finalidades, tais como: estudo da rentabilidade da atividade leiteira; redução dos custos controláveis; identificação e determinação da rentabilidade do produto; instrumento de apoio ao produtor no processo de tomada de decisões seguras e corretas (Lopes e Carvalho, 2000). Lopes et al. (2007) citaram, ainda, diversas outras utilidades dos dados de custo de produção, tais como: cálculo dos valores econômicos para características de gado de leite e quantificar ineficiências econômicas.

Diante desse cenário, objetivou-se estimar o custo de produção de fêmeas bovinas da raça holandesa nas fases de cria e recria e identificar os componentes que exerceram as maiores representatividades sobre os custos operacional efetivo e operacional total da atividade.

\section{Material e Métodos}

Os dados utilizados foram coletados durante os meses de março a junho de 2014, em um sistema de produção de leite, localizado no município de Ijaci $\left(21^{\circ} 10^{\prime} 12^{\prime \prime} S\right.$; 44 $\left.55^{\prime} 31^{\prime \prime W}\right)$ na região sul de Minas Gerais. A produção média diária de leite das 36 vacas da raça holandesa em lactação era de $1.200 \mathrm{~kg}$.
A fase de cria consistiu o período do nascimento até 90 dias de idade, momento em que foi realizado o desaleitamento. As bezerras foram separadas da mãe imediatamente após a constatação do parto, quando se curou o umbigo com iodo $10 \%$, no local do parto. Nos cinco primeiros dias de vida a dieta foi constituída apenas de colostro e leite fornecido duas vezes ao dia; do $5^{\circ}$ até o $60^{\circ}$ dia as bezerras receberam diariamente cinco litros de leite, divididos em duas refeições, mais concentrado (Tabela 1); e do $61^{\circ}$ dia até o desaleitamento as bezerras receberam 2,5 litros de leite e o mesmo concentrado. Durante todo esse período, os animais ainda possuíam acesso à água ad libitum. Todas as bezerras foram alojadas em abrigos individuais, onde permaneceram até o desaleitamento. Os animais receberam vacinas contra botulismo, carbúnculo sintomático, leptospirose, raiva e brucelose.

A fase de recria foi considerada como sendo o período do desaleitamento até o parto que, em média, ocorreu aos 27 meses (810 dias). A idade em que as novilhas atingiram a puberdade, ou seja, peso adotado na propriedade para inseminar as fêmeas $(360 \mathrm{~kg})$, aconteceu por volta dos 630 dias (21 meses) de vida, com um ganho de peso médio diário de 508 gramas. Nessa fase os animais foram alimentados de acordo com a faixa etária (Tabela 2). Além do uso do concentrado, todos os animais, após a fase de aleitamento, tiveram acesso à silagem de milho (Zeamays) e a água era fornecida ad libitum.

Nessa fase, as novilhas foram agrupadas em lotes e as dietas formuladas visando ganho de $750 \mathrm{~g} /$ dia de ganho de peso. O consumo de matéria seca foi mensurado em 2,5\% do peso vivo (NRC, 2001) da formulação da dieta realizada pelo técnico da propriedade. Os animais receberam, ainda, vacinas contra clostridioses, leptospirose, raiva, febre aftosa e brucelose, conforme calendário vacinal praticado na propriedade.

O sistema de produção foi visitado semanalmente para coleta de dados referentes ao desempenho dos animais e registro das despesas. Tais informações foram registradas em uma planilha do MS-Excel $^{\circledR}$ desenvolvida especificamente para estimar o custo de produção das fêmeas bovinas. Tal planilha contemplou a estrutura do custo operacional, proposta por Matsunaga et al. (1976), composta pela soma do custo operacional efetivo e depreciações. Além desses custos, a planilha também contemplava o 
custo total de produção, o qual compreende a soma dos custos fixos (remuneração da terra, remuneração do capital investido, remuneração do empresário, impostos fixos e depreciação).Os itens que compõem o custo operacional efetivo da cria e recria foram divididos em grupos: alimentação, mão-de-obra, sanidade, sêmen, impostos e taxas, energia, aluguel de máquinas utilizadas no arraçoamento e despesas diversas (Lopes et al., 2010).

Para apurar as despesas com a mão-de-obra, foi cronometrado o tempo gasto pelo funcionário responsável para realizar todo o manejo dos animais nas duas fases (cria e recria). Mensurado o tempo destinado às atividades, multiplicou-se esse pelo valor da hora trabalhada do funcionário (Lopes et al., 2010). Visando estimar o custo da mão de obra, o valor estipulado foi baseado no salário mínimo vigente ( $\mathrm{R} \$$ 788,00). As mensurações de tempo foram estimadas a partir da cronometragem realizada por dois pesquisadores (Lopes et al., 2010).

Foi levantado o inventário completo dos bens utilizados, apurando valor e vida útil de cada ativo, sendo, posteriormente, alocados em um dos seguintes grupos: benfeitorias, equipamentos e ferramentas. Nas situações nas quais o pecuarista não dispunha de informações referentes ao valor e à data de aquisição, para a estimativa dos valores atuais, bem como da vida útil restante, foi adotado o critério proposto por Lopes et al.(2004), ou seja, cada uma foi medida sendo atribuído um estado de conservação e registrado um resumo do memorial descritivo, objetivando auxiliar na estimativa do valor atual. Em função da área, do estado de conservação e do padrão de acabamento, foi estimado um valor por $\mathrm{m}^{2}$. $\mathrm{O}$ valor atual utilizado foi produto do valor do $\mathrm{m}^{2}$ pela área da benfeitoria (Lopes et al., 2004). Para o cálculo com a depreciação utilizou-se o método linear (Hoffmann e Funk, 1981), onde depreciação = $($ valor inicial do bem- valor final)/vida útil.

Os dados foram comparados por meio de análises estatísticas descritivas, utilizando-se o aplicativo MS Excel, e agrupados em tabelas objetivando-se melhor comparação, discussão e apresentação dos resultados (Lopes et al., 2004). A pesquisa foi desenvolvida utilizando-se o conceito de estudo de caso, descrito por Yin (1989).

\section{Resultados e Discussão}

Durante os primeiros 90 dias de vida, as bezerras tiveram um custo operacional total de
R \$565,23 (Tabela 3). A alimentação foi responsável por $89,20 \%$ do custo operacional total da produção do sistema de cria, sendo que o leite fornecido foi o item com a maior representatividade $(75,63 \%)$, em função da dieta líquida (leite integral) que os animais receberam; seguido do farelo de soja $(6,30 \%)$ e do farelo de milho $(4,93 \%)$. Os valores desse estudo são superiores aos encontrados por Lopes et al. (2010), de $56,87 \%$ do item leite no COT. Acredita-se que esse fato ocorreu devido à qualidade da mão de obra, onde neste estudo não havia um funcionário responsável pelo setor, mas sim uma escala de trabalho. A cada dia, um empregado era deslocado para realizar a tarefa de aleitamento, diluindo, assim, esse custo com a produção leiteira. Visto à grande representatividade da dieta líquida no custo de produção de bezerras, ressalta-se a importância de reduzir este período, desde que o desempenho animal não seja comprometido. Assim, duas alternativas podem ser utilizadas para se reduzir os custos operacionais durante a fase de aleitamento: Otimização do processo produtivo (despesas operacionais e desperdícios) e diminuir a taxa de mortalidade de bezerras (Santos e Beloni, 2016). Alguns programas de aleitamento buscam oferecer mais leite nos primeiros dias de vida, reduzindo drasticamente esse volume na intenção de estimular o consumo de concentrado (Quigley et al., 1991). O valor do custo do kg de matéria seca do concentrado além de menor, estimula o desenvolvimento das papilas ruminais (Velayudhan et al., 2008). O consumo de 0,7 a 1,0 $\mathrm{kg}$ concentrado inicial/dia pode ser utilizado como um parâmetro para desaleitamento, por indicar que o animal está apto a consumir quantidade adequada de alimentos sólidos capaz de suprir sua demanda nutricional (Sakata e Tamate, 1978). Esse é um dos principais critérios utilizados para o desaleitamento (Boito et al., 2015). Porém, há de se ter muito cuidado quanto a restrição na dieta líquida, pois essa tem correlação positiva com a futura produção de leite (Soberon et al., 2012).

O concentrado representou $11,12 \%$ do COTe $11,30 \%$ do COE (Tabela 3), inferior aos $17,25 \%$ e $18,95 \%$, respectivamente, apresentado por Lopes et al. (2010) e inferior aos 12,2\% do COE, apresentado por Santos e Beloni (2016). A menor ou maior representatividade desse item não necessariamente reflete ser melhor. O desempenho animal deve ser avaliado e, então, ser comparado os valores com este item. A menor representatividade do concentrado pode ser devido 
ao manejo alimentar inadequado, baixa disponibilidade de concentrado aos animais, ou por outro lado pode ser devido ao baixo preço dos insumos dessa dieta ou, ainda, diferença no preço dos demais insumos. Um fator a ser levado em consideração é o alto valor proteico das dietas na fase de cria (Tabela 1) e recria (Tabela 2). Segundo
Campos e Miranda (2012), o excesso de proteína sobrecarrega o fígado e os rins, com alto custo energético. Também significa maior custo financeiro, elevando o custo com alimentação, além de poderem causar problemas metabólicos nos animais.

Tabela 1. Composição média da dieta sólida de fêmeas bovinas da raça holandesa durante a fase de cria (5 a 90 dias de idade).

\begin{tabular}{lccccc}
\hline \multicolumn{1}{c}{ Ingrediente } & kg/animal/dia & MS & Pomposição bromatológica (\%) & FDN & NDT \\
\hline Milho moído & 0,50 & 88,60 & 8,90 & 10,00 & 90,00 \\
Farelo de soja & 0,33 & 88,56 & 47,64 & 14,81 & 72,70 \\
Feno de tifton 85 moído & 0,14 & 49,00 & 12,69 & 84,00 & 6,08 \\
Sal mineral & 0,03 & 92,33 & 0,00 & 0,00 & 0,00 \\
\hline Total & 1,00 & 89,20 & 20,52 & 15,98 & 69,83 \\
\hline
\end{tabular}

Fonte: Dados da pesquisa

MS: Matéria seca; PB: Proteína bruta; FDN: Fibra de detergente neutro; NDT: Nutrientes digestíveis totais.

Tabela 2. Composição média da dieta sólida das fêmeas bovinas da raça holandesa em diferentes períodos na fase de recria, em kg/animal/dia.

\begin{tabular}{llccccc}
\hline & & & \multicolumn{3}{c}{ Composição bromatológica (\%) } \\
\cline { 4 - 7 } Idade & Ingrediente & kg/animal/dia & MS & PB & FDN & NDT \\
\hline De 3 a 6 meses & Milho & 0,50 & 88,60 & 8,90 & 10,00 & 90,00 \\
& Farelo de soja & 1,00 & 88,56 & 47,64 & 14,81 & 72,70 \\
& Ureia & - & 98,00 & 262,00 & 0,00 & 0,00 \\
& Sal mineral & 0,07 & 92,33 & 0,00 & 0,00 & 0,00 \\
\hline & Total & 1,57 & 89,62 & 30,80 & 10,80 & 71,82 \\
\hline & Milho & 0,50 & 88,60 & 8,90 & 10,00 & 90,00 \\
& Farelo de soja & 1,00 & 88,56 & 47,64 & 14,81 & 72,70 \\
& Ureia & 0,05 & 98,00 & 262,00 & 0,00 & 0,00 \\
& Sal mineral & 0,15 & 92,33 & 0,00 & 0,00 & 0,00 \\
\hline & Total & 1,70 & 94,97 & 19,16 & 5,22 & 34,69 \\
\hline A partir de 14 meses & Milho & - & 88,60 & 8,90 & 10,00 & 90,00 \\
& Farelo de soja & 1,00 & 88,56 & 47,64 & 14,81 & 72,70 \\
& Ureia & 0,10 & 98,00 & 262,00 & 0,00 & 0,00 \\
& Sal mineral & 0,15 & 92,33 & 0,00 & 0,00 & 0,00 \\
\hline & Total & 1,25 & 91,69 & 57,42 & 10,05 & 60,29 \\
\hline
\end{tabular}

Fonte: Dados da pesquisa

No presente estudo, o feno representou $1,83 \%$ do COT e $1,88 \%$ do COE, tendo quase o mesmo percentual do item mão de obra (Tabela 3). $\mathrm{O}$ fornecimento de feno durante a fase de aleitamento é pouco comum em sistemas intensivos de criação de bezerras (Liziere et al., 2002). Ainda, segundo esses autores, não houve diferenças significativas para consumo e ganho de peso de bezerros desaleitados aos trinta dias de idade que receberam dietas com ou sem a participação do feno. Porém, de acordo com Hill et al. (2007), a ingestão de forragem durante a fase de aleitamento em bezerros favorece $o$ desenvolvimento físico do rúmen. Khan et al.
(2011) relataram que o uso de volumosos é muito importante para o desenvolvimento fisiológico, do tamanho e da musculatura do rúmen, devido a mudança no perfil de fermentação. Vários estudos mostram que o desenvolvimento ruminal, no que se refere a quantidade e tamanho de papilas, que vão permitir a absorção de produtos finais da fermentação, contribuindo com o atendimento das necessidades energéticas do animal, depende do consumo de alimentos concentrados (Khanet al., 2011; Monteiro et al., 2015, Silva et al., 2015). Porém, outra corrente de pesquisadores tem mostrado que embora ainda não seja estimulado o uso de feno durante o aleitamento (Terré et al., 
2013) apresentam um efeito benéfico deste alimento na redução da acidose metabólica da bezerra, fato que funcionaria como uma retroalimentação para a ingestão de mais concentrado.

Tabela 3. Composição do custo operacional efetivo (COE) e custo operacional total (COT) de fêmeas bovinas da raça holandesa na fase de cria.

\begin{tabular}{lccc}
\hline Especificação & R\$ & \% COE & \% COT \\
\hline Alimentação & 504,2 & 89,66 & 88,29 \\
Leite & 427,5 & 76,02 & 74,86 \\
Farelo de Milho & 27,90 & 4,96 & 4,88 \\
Farelo de Soja & 35,64 & 6,34 & 6,24 \\
Feno & 10,46 & 1,88 & 1,83 \\
Sal Mineral & 2,70 & 0,49 & 0,47 \\
Mão de obra & 10,9 & 1,94 & 1,90 \\
Fornecimento de leite & 5,85 & 1,04 & 1,02 \\
Fornecimento de concentrado & 1,51 & 0,27 & 0,26 \\
Fornecimento de água & 3,53 & 0,62 & 0,61 \\
Sanidade & 2,5 & 0,44 & 0,44 \\
Iodo & 2,5 & 0,44 & 0,44 \\
Sêmen & 44,73 & 7,95 & 7,83 \\
\hline Custo operacional efetivo & 562,33 & 100,00 & \\
(COE) & 8,70 & - & 1,52 \\
\hline Depreciação* & 571,03 & - & 100,00 \\
\hline Custo operacional total & & \\
(COE + depreciação) & &
\end{tabular}

*Abrigo individual; baldes plásticos; corrente; e cercas. **Preço de venda do leite estimado em $\mathrm{R} \$ 0,90$

O item mão de obra representou $1,90 \%$ do COT e $1,94 \%$ do COE durante a fase de cria (Tabela 3). Vale salientar que o tempo com aplicação de medicamentos, período para buscar o bezerro do piquete maternidade e fornecimento do colostro não foram computados. Embora a representatividade seja baixa, a importância desse item é muito grande, uma vez que são os colaboradores os responsáveis pelo sucesso final da atividade; pois são eles quem fornecem a alimentação aos animais, bem como observam possíveis doenças e injúrias. De acordo com De Passillé et al. (2011), o comportamento de tratadores também afeta o desempenho dos animais. Bezerros podem desenvolver medo de seus tratadores, em virtude de tratamentos aversivos, fato que pode levar os animais a reduzir a ingestão de matéria seca, apresentar diarreias e, consequentemente, baixo desempenho.

$\mathrm{Na}$ fase de recria, o custo operacional total de uma novilha ao parto ficou em $\mathrm{R} \$ 6.606,43$ (Tabela 4). Considerando o período dessa fase (810 dias), o sistema de produção teve uma despesa média de $\mathrm{R} \$ 8,15 /$ dia/animal. Tais valores evidenciam a importância financeira também desta categoria animal. A alimentação foi o item de maior representatividade no custo operacional total, representando 59,53\%; valor superior aos $55,69 \%$ apresentado por Santos; Lopes (2014). Embora, o principal constituinte do custo nessa fase também seja a alimentação, semelhante à fase de aleitamento, a constituição desta dieta é bastante diferente. Nela, a forragem é o item de maior representatividade. Os animais, nessa fase, obtiveram ganho de peso médio (GPM) de 503gramas/dia, inferior aos 680gramas/dia, encontrados por Signoretti et al. (2013). O GPM ideal, mencionado por Santos et al. (2010), é entre 650 a 780 gramas/dia. O GPM, obtido pelos animais desta pesquisa, contribui para elevar o custo de produção, uma vez que aumenta a quantidade de animais na fase de recria, bem como retarda a idade à parição. Isso pode ser considerado um ponto fraco na propriedade. Acredita-se que ele possa ter ocorrido devido à oferta e ao consumo de concentrado (Tabela 2) menor do que o preconizado por Santos et al. (2010) e pelo NRC (2001), de 2,5kg/dia. O GPM tem sido uma preocupação de pesquisadores, técnicos e pecuaristas, pois diversos artigos reportam que ganhos excessivos, acima de 700gramas/dia, trazem como consequência a deposição de gordura no úbere, ocasionando resultados negativos no potencial de produção de leite (Pirlo et al., 1997). No entanto, Daniels et al. (2009) compararam diferentes ganhos de peso diário em novilhas de leite e observaram que, ganhos de 950gramas/dia comparado com 650gramas/dia não influenciou o desenvolvimento da glândula mamária, indicando que ganhos mais altos podem ser utilizados na intenção de reduzir a idade ao primeiro parto.

Práticas de manejo que propiciem melhoras no desempenho, sem aumentar o custo, devem ser estimuladas e implantadas. Ações como adaptar corretamente bezerras recém-desaleitadas à nova fase (recria), reduzir a exposição dos animais ao sol excessivo e utilizar coberturas sobre o cocho contribuem no sentido de otimizar o potencial genético dos animais (Silva et al., 2012). Outro fator de grande importância refere-se ao comportamento dos colaboradores, no sentido de manter a padronização das rotinas, alimentares e práticas de manejo (Bond et al., 2012). Assim, melhorias no ganho de peso diário irão proporcionar idade ao primeiro parto inferior a 30 meses, aumentando a renovação de matrizes, aumento da quantidade de matrizes em lactação ou possibilidade de vendê-las, consequentemente 
aumentando a receita do sistema de produção (Lopes et al., 2009).

Tabela 4. Composição do custo operacional efetivo (COE) e custo operacional total (COT) de fêmeas bovinas da raça holandesa na fase de recria.

\begin{tabular}{|c|c|c|c|}
\hline Especificação & $\mathbf{R} \$$ & $\doteqdot \mathrm{COE}$ & $\% \mathrm{COT}$ \\
\hline Aquisição bezerra & 518,66 & 7,86 & 7,85 \\
\hline Alimentação & $3.932,83$ & 59,65 & 59,53 \\
\hline Forragem & $1.918,63$ & 29,10 & 29,04 \\
\hline Farelo de Soja & $1.548,00$ & 23,48 & 23,43 \\
\hline Farelo de Milho & 102,3 & 1,55 & 1,55 \\
\hline Ureia & 177,6 & 2,70 & 2,69 \\
\hline Sal Mineral & 186,3 & 2,82 & 2.82 \\
\hline Mão de obra & $1.988,12$ & 30,15 & 30,10 \\
\hline Fornecimento de volumoso & 369,18 & 5,60 & 5,59 \\
\hline $\begin{array}{l}\text { Fornecimento de } \\
\text { concentrado }\end{array}$ & 165,8 & 2,51 & 2,50 \\
\hline $\begin{array}{l}\text { Encher a carreta de } \\
\text { silagem }\end{array}$ & $1.453,14$ & 22,04 & 22,00 \\
\hline Despesa com reprodução & 14,70 & 0,22 & 0,22 \\
\hline Sanidade & 56,23 & 0,85 & 0,85 \\
\hline Vacina de Brucelose & 2,00 & 0,03 & 0,03 \\
\hline Vacina de Febre aftosa & 6,00 & 0,09 & 0,05 \\
\hline Vacina de Clostridioses & 3,00 & 0,04 & 0,04 \\
\hline Vacina de Leptospirose & 1,78 & 0,02 & 0,02 \\
\hline Vacina de Raiva & 1,60 & 0,02 & 0,02 \\
\hline Vermífugos & 41,85 & 0,63 & 0,62 \\
\hline Aluguel de Máquinas & 82,50 & 1,25 & 1,24 \\
\hline $\begin{array}{l}\text { Custo operacional efetivo } \\
\text { (COE) }\end{array}$ & $6.593,04$ & 100,00 & - \\
\hline Depreciação* & 13,39 & - & 0,20 \\
\hline $\begin{array}{l}\text { Custo operacional total } \\
\text { (COE + depreciação) }\end{array}$ & $6.606,43$ & - & 100,00 \\
\hline
\end{tabular}

$\mathrm{Na}$ intenção de otimizar essa despesa, esforços gerenciais devem ser adotados para produzir uma forragem de qualidade, economicamente viável e que permita com que os animais expressem todo o potencial de desempenho.

As despesas com mão de obra representaram $30,10 \%$ do custo operacional total na fase de recria de novilhas (Tabela 4). A maior parte do tempo foi destinado ao enchimento de carretas com silagem. Embora os procedimentos operacionais foram realizados corretamente, a opção da aquisição de vagão forrageiro com enchimento automático deve ser analisada em um estudo de viabilidade econômica. Essa opção ocasionaria um aumento nos investimentos, mas otimizaria o tempo dos colaboradores com esta atividade, além da homogênea retirada da forragem do silo. $\mathrm{Na}$ literatura, o percentual das despesas com mão de obra varia de 12 a 16,5\% (Santos e Lopes, 2014), evidenciando que os valores obtidos no presente estudo estão elevados.

As despesas com aquisição de animais da fase de cria foi o terceiro item de maior representatividade, correspondendo por $7,86 \%$ do COE. Ressalta-se a importância de se ter bons índices na fase de cria, quando essa acontece na propriedade, ou ter muito cuidado no momento de adquirir esses animais de terceiros, pois esses animais adquiridos, segundo Lopes et al. (2010) representaram 22,81\% do COE na fase de recria, sendo assim não devem ter baixos desempenhos produtivos, pois caso tenham, elevariam ainda mais o custo. A compra de animais nas fases de cria ou recria não é uma prática muito adotada, uma vez que criando os animais na própria propriedade é possível obter um melhoramento genético através da escolha minuciosa do sêmen, além de prevenir a entrada de doenças dentro do sistema de produção, o que traria prejuízos financeiros ao produtor (Lopes et al., 2010).

Lopes et al. (2010) relataram que a aquisição de bezerras representou $19,39 \%$ do custo operacional total; porém, o período da recria foi do desaleitamento até a inseminação artificial e não até o parto, como no presente estudo. As despesas com aluguel de máquinas (tratores) representaram $1,25 \%$ das despesas operacionais totais na recria de novilhas leiteiras (Tabela 5). Esses valores foram muito mais baixos do que os encontrados por Lopes et al. (2010).

Tabela 5. Análise de rentabilidade de uma fêmea bovina leiteira na fase de recria, no período de março a junho de 2014.

\begin{tabular}{lc}
\hline \multicolumn{1}{c}{ Especificação } & $\mathbf{R} \$$ \\
\hline Receita (1) & $5.000,00$ \\
Custo operacional efetivo (COE) (2) & $6.593,04$ \\
Custo operacional total (COT) (3) & $6.606,43$ \\
Depreciação (4) & 13,39 \\
Custo fixo (5) & $1.147,83$ \\
Custo variável (6) & $6.654,33$ \\
Custo total (6+5) & $7.802,16$ \\
Margem bruta (1- 2) & $-1.593,04$ \\
Margem líquida (1-3) & $-1.594,87$ \\
Resultado (1-(6+5)) & $-2.802,16$
\end{tabular}

Fonte: Dados da pesquisa

$\mathrm{Na}$ intenção de simular uma análise de rentabilidade, visto que os animais não foram efetivamente comercializados, atribuiu-se um 
preço de venda no valor de $\mathrm{R} \$ 5.000,00$; valor esse comumente praticado na região para novilhas com o mesmo padrão genético do presente estudo (Santos e Lopes, 2014). Na atual situação, o sistema de produção estudado apresentou margens bruta e líquida, bem como o resultado negativos (Tabela 5), evidenciando que criar e recriar fêmeas bovinas da raça holandesa não foi viável economicamente. Acredita-se que os vários erros de manejo observados, no que diz respeito ao manejo zootécnico, tiveram como consequência ganhos de pesos menores do que os considerados ideais, sendo uma das possíveis causas do prejuízo. Além disso, fatores como mão de obra em excesso e ociosa também podem ser consideradas fatores para o insucesso.

Muito embora, pautado apenas na questão zootécnica, também devam ser analisados em paralelo outros fatores, tais como disponibilidade dessa categoria animal no mercado local, o risco de transmissão de doenças em caso de aquisição de fêmeas e a procedência genética das novilhas. Uma das utilidades de se estimar o custo de produção de novilhas é compará-lo com o preço de mercado no intuito de se decidir a melhor opção: criar, comprar ou terceirizar a criação desses animais. Cada opção tem vantagens e limitações. A compra, muitas vezes não permite conhecer os ancestrais, bem como o histórico sanitário da novilha. Porém, dependendo da região, encontra-se a preços baixos. Com relação a terceirização, o animal sai da fazenda, ou seja, sabe-se a genealogia, normalmente tem funcionário especializado para o manejo das bezerras e disponibiliza área para agricultura e/ou produção de leite. Os agravantes são: contato com animais de outras propriedades, permitindo a transmissão de doenças; distância a ser percorrida até o centro de recria (Lopes et al.

, 2010). Porém, nenhum desses fatores eximem de responsabilidade os gestores, que são fundamentais para melhorar a eficiência produtiva desta categoria animal.

Considerando que os indicadores de rentabilidade margem bruta e líquida e o resultado foram negativos (Tabela 5), faz-se necessário ressaltar as ineficiências do sistema de produção estudado, observados a partir de um formulário de diagnóstico aplicado na propriedade (Lopes e Reis, 2015). Dentro os pontos fracos que foram diagnosticados destacam-se: a quantidade de litros de leite fornecido as bezerras variam de acordo com o funcionário, a não realização da higienização do úbere antes da ordenha do colostro, não avalia qualidade do colostro, não há banco de colostro na propriedade, não há constância no horário de fornecimento de leite, bezerras em abrigos individuais fixos e com diarreia, uso de medicamentos sem orientação técnica, mão de obra ociosa e sem funções definidas. Acredita-se que esses pontos fracos, se corrigidos, deixem de ser ameaças e sejam transformados em oportunidades, aumentando a rentabilidade e a lucratividade da propriedade rural.

\section{Conclusão}

Por apresentar margens bruta e líquida, bem como resultado negativos, o sistema de produção não foi viável economicamente. Isso ocorre devido a ineficiências no sistema de produção. Para reduzir as perdas é necessário diagnosticar e solucionar os problemas encontrados. Sugere-se a aplicação de ferramentas de gestão no intuito de minimizar as ameaças e maximizar as oportunidades.

O custo operacional total de uma fêmea bovina da raça holandesa nas fases de cria e recria foi de $\mathrm{R} \$ 571,03$ e $\mathrm{R} \$ 6.606,43$, respectivamente. Os itens componentes do COE e do COT, respectivamente, que exerceram maiores representatividades sobre os custos da atividade na fase de cria foram, em ordem decrescente, alimentação $(89,66 \%, 88,29 \%)$, sêmen $(7,95 \%$, $7,83 \%)$ e mão-de-obra $(1,94 \%, 1,90 \%)$. Na fase de recria foram, respectivamente, em ordem decrescente, alimentação $(59,65 \%, 59,53 \%)$, mão de obra $(30,15 \%, 30,10 \%)$ e aquisição de bezerras $(7,86 \%, 7,85 \%)$. A depreciação representou $\mathrm{R} \$ 8,70(1,52 \%)$ e $\mathrm{R} \$ 13,39(0,20 \%)$ do COT, na fase de cria e recria, respectivamente.

\section{Conflito de Interesse}

Os autores declaram não existir conflito de interesse,

\section{Referências}

Boito, B.; Menezes, L.F.G.; Ziech, M.F.; Kuss, F.; Lisbinski, E.; Fiorelli, A. Uso de sucedâneo em substituição ao leite no desempenho de bezerros da raça holandesa durante a cria e recria. Ciência Animal Brasileira, 16(4):498-507, 2015.

Bond, G.B.; Almeida, R.; Ostrensky, A.; Molento, C.F.M. Métodos de diagnóstico e pontos críticos de bem-estar de bovinos leiteiros. Ciência Rural, 42(7):1286-1293, 2012. 
Campos, O. F.; Miranda, J.E.C. Gado de leite: o produtor pergunta, a Embrapa responde. Brasília, Embrapa Informação Tecnológica, 2012. 174p.

Caselli, A.M.; Assis, M.V.B. Estudo da viabilidade econômica de uma propriedade produtora de leite e bovinos de corte. Temas em Administração, 4(2):38-46, 2011.

Daniels, K.M.; Mcgilliard, M.L.; Meyer, M.J. Effects of body weight and nutrition on histological mammary development in Holstein heifers. Journal of Dairy Science, 92(2): 499-505, 2009.

De Passillé, A.M.; Borderas, T.F.; Rushen, J. Weaning age of calves fed a high milk allowance by automated feeders: effects on feed, water, and energy intake, behavioral signs of hunger, and weight gains. Journal of Dairy Science, 94(3): 1401-1408, 2011.

Hill, T.M.; Bateman, H.G.; Aldrich, J.M.; Schlotterbeck, R.L. Effects of feeding rate of milk replacers and bedding material for calves in a cold naturally ventilated nursery. The Professional Animal Scientist, 23(6): 656664, 2007.

Hoffman, P.C.; Funk, D.A. Applied dynamics of dairy replacement growth and management. Journal Dairy Science, 9(9): 2504-2616, 1981.

Khan, M.A.; Weary, D.M.; Von Keyserlingk, M.A.G. Effects of milk ration on solid feed intake, weaning, and performance in dairy heifers. Journal of Dairy Science, 94(3): 1071-1081, 2011.

Lizieire, R.S.; Cunha, D.N.F.V.; Martuscello, J.A.; Campos, O.F. Fornecimento de volumoso para bezerros pré-ruminantes. Ciência Rural, 32(5): 835-840, 2002.

Lopes, M.A.; Carvalho, F.M. Custo de produção do leite. Lavras: UFLA (Boletim Agropecuário, 32), 2000. 42p.

Lopes, M.A.; Demeu, F.A.; Santos, G.; Cardoso, M. G. Impacto econômico do intervalo de partos em rebanhos bovinos leiteiros. Ciência e Agrotecnologia. 33(edição especial): 19081914. 2009.

Lopes, M.A.; Franco Neto, A.; Santos, G.; Demeu, F.A.; Lopes, L.M.F.; Rezende, S.M. Custos de produção de fêmeas bovinas da raça holandesa nas fases de cria e recria em um sistema de produção de leite no sul de Minas Gerais. Boletim de Indústria Animal, 67(1):9-15, 2010.
Lopes, M.A.; Lima, A.L.R.; Carvalho, F.M.; Reis, R.P.; Santos, I.S.; Saraiva, F. H. Controle gerencial e estudo da rentabilidade de sistemas de produção de leite na região de Lavras (MG). Ciência e Agrotecologia, 28(2): 88392, 2004

Lopes, M.A.; Cardoso; M.G.; Carvalho, F.M.; Lima, A.L.R.; Dias, A.S.; Carmo, E.A. Efeito do tipo de sistema de criação nos resultados econômicos de sistemas de produção de leite na região de Lavras (MG) nos anos 2004 e 2005. Ciência Animal Brasileira, 8(3): 359371, 2007.

Lopes, M.A.; Reis, E.M.B. Formulário de diagnóstico da propriedade leiteira. Lavras: UFLA, 2015. 19p.

Matsunaga, M.; Bemelmans, P.F.; Toledo, P.E.N.; Dulley, R.D.; Okawa, H.; Pedroso, I.A. Metodologia de custo de produção utilizado pelo IEA. Boletim do Instituto de Economia Agrícola, 23(1): 123-139, 1976.

Monteiro, C.; Perri, S.; Carvalho, R.; Carvalhal, R. Desenvolvimento do rúmen de bovinos no período pré-natal. Revista Científica Eletrônica de Medicina Veterinária, 24(1): 1-13, 2015.

National Research Council - NRC. Nutrient requeriments of dairy cattle. $7^{\text {th }}$. Washington: D.C, 2001. 381p.

Pirlo, G. Cost of rearing growing heifers to an optimum age for first parturition. Informatore Agrário, 53(1): 9-12, 1997.

Quigley, J.D.; Smith, P.; Heitmann, R.N. Changes in plasma volatile fatty acids in response to weaning and feed intake in young calves. Journal of Dairy Science, 74(1): 258-263, 1991.

Sakata, T.; Tamate, H. Rumen Epithelial cell proliferation accelerated by rapid increase in intraruminal butyrate. Journal of Dairy Science, 61(8): 1109-1113, 1978.

Santos, G.; Lopes, M.A. Indicadores econômicos de sistemas de produção de leite em confinamento total com alto volume de produção diária. Ciência Animal Brasileira, 15(2):239-248, 2014

Santos, G.; Beloni, T. Custo de produção de bezerras e novilhas leiteiras - Um estudo de caso. Revista IPECEGE, 2(1): 1-15, 2016.

Santos, S.A.; Campos, J.M.S.; Valadares Filho, S.C.; Oliveira, A.S.; Souza, S.M.; Santiago, A.M.F. Balanço de nitrogênio em fêmeas leiteiras em confinamento alimentadas com 
concentrado à base de farelo de soja ou farelo de algodão. Revista Brasileira de Zootecnia, 39(5): 1135-1140, 2010.

Signoretti, R.D.; Resende, F.D.; Drubi, G.M.; Souza, F.H.M.; Dib, V.; Oliveira, E.M. Desenvolvimento corporal de novilhas leiteiras suplementadas com minerais inorgânicos e orgânicos em pastejo na época das águas. Revista Brasileira de Saúde e Produção Animal, 14(2):336-349, 2013.

Silva, J.S.; Borges, A.L.C.; Duque, A.C.A.; Coutinho, R.A.; Lopes, F.C.F.; Silva, R.R. Estratégias de aleitamento e fornecimento de alimentos sólidos para bezerras jovens. Caderno de Ciências Agrárias, 7(1):178190, 2015.

Silva, T.P.D.; Oliveira, R.G.; Sousa Junior, S.C.; Santos, K.R. Efeito da exposição à radiação solar sobre parâmetros fisiológicos e estimativa do declínio na produção de leite de vacas mestiças (Holandês X Gir) no sul do estado do Piauí. Comunicata Scientiae, 3(4): 299-305, 2012.

Soberon, F.; Raffrenato, E.; Everett, R.W.; Van Amburgh, M.E. Preweaning milk replacer intake and effects on long-term productivity of dairy calves. Journal of Dairy Science, 95(2): 783-793. 2012.

Terré, M.; Pedrals, E.; Dalmau, A.; Bach, A. What do preweaned and weaned calves need in the diet: A high fiber content or a forage source? Journal of Dairy Science, 96(8): 5217-5225, 2013.

Velayudhan, B.T.; Daniels, K.M.; Horrel, D.P.; Hill, S.R.; Mcgilliard, M.L.; Corl, B.A.; Jiang H.; Akers, R.M. Developmental histology, segmental expression, and nutritional regulation of somatotropic axis genes in small intestine of preweaned dairy heifers. Journal of Dairy Science, 91(9): 3343-3352, 2008.

Yin, R.K. Case study research: design and methods. Newbury Park: Sage, 1989. 145p. 